\title{
Role of obligatory banning of smoking in 2014 - 2016 on the smoking habits of a group of men in Mosul, Iraq
}

\begin{tabular}{cc}
\hline Rasha Ramzi Ahmed ${ }^{2 *}$ & Namir Al-Tawil $^{2}$ \\
\hline Abstract &
\end{tabular}

Background and objective: Smoking is a risk factor for major non-communicable diseases and is an important cause of preventable death. Smoking cessation is a challenge for both the smoker and the health care provider. This study aimed to assess the role of obligatory banning of smoking in 2014 - 2016 on the smoking habits of a group of men in Mosul city.

Methods: A convenience sample of 500 male smokers, aged 18 years and above who were living in Mosul on June 10, 2014 (the day of Mosul invasion by the Islamic State in Iraq and Sham, ISIS) and stayed living in the city for three years after that, were included in the study. The study design was cross-sectional, and data were collected by direct interview.

Results: One fifth (100 persons) of the participants quit smoking (without medications) during banning. More than one third $(36 \%)$ of them quit due to the high price of cigarettes. Unfortunately, the majority $(75 \%)$ returned back to smoking after the liberation of Mosul. The factors found to be significantly associated with the high rate of quitting included short duration of smoking ( $<9$ years) before the banning period $(P=0.006)$, trial of quitting smoking before banning $(P=0.001)$, history of light smoking $(P=0.003)$, and smoking among second degree relatives, compared with the first degree relatives $(P=0.025)$.

Conclusion: The rate of cessation was relatively low compared with the possible punishments by the ISIS. Smoking cessation is still a challenge to public health practitioners, as many factors play a role.

Keywords: Smoking banning; ISIS; Mosul; Quitting smoking.

\section{Introduction}

Tobacco use is a risk factor for major non-communicable diseases like ischemic heart disease and lung cancer. It is an important cause of preventable death, and without urgent actions to alleviate such a burden, one billion people will die from tobacco in the $21^{\text {st }}$ century. ${ }^{1}$ However, only 37 countries( $15 \%$ of the population) have completely banned all forms of tobacco advertising, promotion, and sponsorship by 2018. ${ }^{2}$ Cigarette smoking can be viewed mainly as a psychological habit with accompanying pharmacological and social satisfactions and reinforcements. ${ }^{3}$ Smokers are more likely to have a psychiatric disorder than are non-smokers.
Conversely, individuals with a psychiatric disorder are almost twice as likely to be smokers as individuals without a psychiatric disorder. ${ }^{4}$ Nicotine is considered to be the third most addictive substance after heroin and cocaine. Complex and not fully elucidated destructive neurobiological and behavioral mechanisms compose the personality of the typical addicted smoker who desires but fails to quit. ${ }^{5}$ Quitting usually takes $\geq 2$ 3 attempts before finally being successful. ${ }^{3}$ There is scant research internationally on the effects of obligatory banning of smoking on smoking behavior, and it mainly focused on workplace bans which are of a quite different nature to this study.

${ }^{1}$ Nineveh Directorate of Health, Nineveh, I raq.

2 Department of Community Medicine, College of Medicine, Hawler Medical University, Erbil, I raq.

* Correspondence: rasharamze@yahoo.com 
Smokers who do not work in a workplace may be unaffected by workplace bans. The main objective of the smoking bans was to protect non-smokers from exposure to 'second hand smoke' rather than studying the effect on the smoking patterns. ${ }^{6}$ Up to the researcher's knowledge, no study had been carried out to investigate the behavior of smokers during the period of banning smoking in Mosul. There is inconsistency in the results of epidemiological studies regarding the psychological and physiological effects on smokers after quitting smoking. This study was carried out to assess the role of obligatory banning of smoking on the smoking habits of a group of men in Mosul city from October 2014 to the liberation of each participant in 2016 (according to the residence of each one, as each one was liberated in a different day).

\section{Methods}

A cross-sectional study was conducted in Mosul city from December 1, 2017, to December 31, 2018. A convenience sampling method was used to collect data from 500 men aged 18 years and over who had been smoking at the time of the ISIS (Islamic State in Iraq and Syria) invasion on June 10, 2014, and stayed living in Mosul city during the three years of invasion. A pilot study was carried out in January 2018 after obtaining verbal consent from twenty smokers in public places through an interview. The pilot study results were considered for the final adjustment of the questionnaire and determining the time needed for filling the questionnaire before starting the study.

\section{Data collection tool:}

A questionnaire designed by the researchers was constructed for data collection. The majority of eligible men were willing to participate in the study. However, some refused to participate with a non-response rate of $3 \%$. The data were collected by interview, which was done twice weekly from February 1, 2018, through August 31, 2018. Each interview took approximately $15-20$ minutes. It was carried out at the participants' homes, workplaces (private and public offices, and colleges), public places (like restaurants, coffee shops, and markets), or through mobile phone and social media applications such as Viber and WhatsApp. The following equation was used to calculate the score of socioeconomic status (SES):

SES $=[$ Education + Occupation $+($ House ownership $\times 0.5)+($ Car ownership $\times 0.1)+$ ((age-20) /100) - (Retired/unemployed/ deceased)]. ${ }^{7}$

The minimum score was 0 for an unemployed, illiterate, young manual laborer with no house and car. The maximum score was 14.05 for a medical doctor of 63 years (the usual age of retirement in Iraq) with a car and a house. The calculated SES score was divided into three equal levels: low SES score $(<5)$, middle SES (5-9), high SES $(\geq 10){ }^{7}$

\section{Statistical analysis:}

Data were analyzed using the statistical package for the social sciences (SPSS, version 22). Chi square test of association and Fisher's exact test were used to compare proportions. A $P$ value of $\leq 0.05$ was considered statistically significant. Ethical approval was obtained from the Ethics committee of the college of medicine, Hawler Medical University (No. 5; dated October 25, 2017). Verbal informed consent was obtained from each participant before being enrolled in the study.

\section{Results}

The total number of the participants was 500 men. Their mean age \pm SD was 39.65 \pm 12.70 years, ranging from 22 to 78 years. The median was 38 years. The place of birth of the majority of the sample (94.6\%) was urban areas. One third of the sample was of low SES, $49.8 \%$ we re of medium SES, and $17 \%$ were of high SES. The prevalence of obesity was $22.4 \%$, and around half $(50.6 \%)$ of the men were not practicing exercise. Results also showed 
that 100 persons (20\%) stopped smoking as presented in Table 1. More than half of during the banning period, either the participants (55.4\%) continued smoking completely or have smoked occasionally, but with fewer cigarettes (Table 1).

Table 1: Basic characteristics of the studied population and smoking status during banning.

\begin{tabular}{|c|c|c|}
\hline Basic characteristics & No. & (\%) \\
\hline \multicolumn{3}{|l|}{ Age group (years) } \\
\hline$<30$ & 132 & (26.4) \\
\hline $30-39$ & 135 & $(27.0)$ \\
\hline $40-49$ & 120 & $(24.0)$ \\
\hline $50-59$ & 67 & $(13.4)$ \\
\hline$\geq 60$ & 46 & $(9.2)$ \\
\hline \multicolumn{3}{|l|}{ Place of birth } \\
\hline Urban & 473 & $(94.6)$ \\
\hline Rural & 27 & $(5.4)$ \\
\hline \multicolumn{3}{|l|}{ Socio-economic status } \\
\hline Low & 166 & (33.2) \\
\hline Middle & 249 & $(49.8)$ \\
\hline High & 85 & $(17.0)$ \\
\hline \multicolumn{3}{|l|}{ Body Mass Index (BMI) Kg/m² } \\
\hline Normal and underweight & 189 & $(37.8)$ \\
\hline Overweight & 199 & $(39.8)$ \\
\hline Obese & 112 & $(22.4)$ \\
\hline \multicolumn{3}{|l|}{ Physical activity } \\
\hline None & 253 & $(50.6)$ \\
\hline On occasion & 117 & $(23.4)$ \\
\hline Once/week & 55 & $(11.0)$ \\
\hline 2-3times/week & 37 & $(7.4)$ \\
\hline Daily & 38 & $(7.6)$ \\
\hline \multicolumn{3}{|l|}{ Smoking status during the banning } \\
\hline Quit & 72 & $(14.4)$ \\
\hline Quit, with short periods of smoking ( $<10$ days) & 28 & $(5.6)$ \\
\hline Continued with periods of quitting & 10 & $(2.0)$ \\
\hline Continued but fewer cigarettes. & 277 & $(55.4)$ \\
\hline Continued but the same number of cigarettes. & 79 & $(15.8)$ \\
\hline Continued but increased number of cigarettes. & 34 & $(6.8)$ \\
\hline Total & 500 & $(100.0)$ \\
\hline
\end{tabular}


Methods of stopping smoking before and during banning:

Results showed that before banning 158 out of the 500 persons $(31.6 \%)$ had a history of attempts to quit smoking, $81 \%$ $(128 / 158)$ of them stopped smoking suddenly, $17.7 \%$ stopped it gradually, and the rest $(1.3 \%)$ took a smoking cessation therapy. During banning, 100 out of 500 quit smoking; $67 \%$ stopped smoking suddenly, and $33 \%$ stopped it gradually.
After the liberation of Mosul city, $75 \%$ of quitters returned to smoking. Table 2 shows that around one third of those who had quit smoking before and during banning mentioned that their physical fitness and appetite had improved after quitting. The table also shows that around one third of them had experienced a feeling of eagerness for cigarettes, nervousness, and others mentioned in the table.

Table 2: Withdrawal symptoms of those who quit smoking before and during banning.

\begin{tabular}{lcccc}
\hline & \multicolumn{2}{c}{$\begin{array}{c}\text { Before banning } \\
\mathbf{N}=\mathbf{1 4 3}^{*}\end{array}$} & \multicolumn{2}{c}{$\begin{array}{c}\text { During banning } \\
\mathbf{N}=\mathbf{8 5}^{* *}\end{array}$} \\
Withdrawal symptoms $\dagger$ & No. & $(\%)$ & No. & $(\%)$ \\
\hline Headache & 32 & $(22.4)$ & 32 & $(37.6)$ \\
Common cold symptoms & 5 & $(3.5)$ & 5 & $(5.9)$ \\
Nervousness & 62 & $(43.4)$ & 39 & $(45.9)$ \\
Fatigability & 4 & $(2.8)$ & 2 & $(2.4)$ \\
Eager for cigarettes & 47 & $(32.9)$ & 34 & $(40.0)$ \\
Inability to concentrate & 14 & $(9.8)$ & 17 & $(20.0)$ \\
Improved physical fitness & 63 & $(44.1)$ & 27 & $(31.8)$ \\
Increased appetite & 55 & $(38.5)$ & 29 & $(34.1)$ \\
Disappearance of skin discoloration & 3 & $(2.1)$ & 2 & $(2.4)$ \\
Working better & 30 & $(21.0)$ & 16 & $(18.8)$ \\
Visual and sleep disturbances & 3 & $(2.1)$ & 3 & $(3.5)$ \\
Others & 3 & $(2.1)$ & 0 & $(0.0)$ \\
\hline
\end{tabular}

*143 out of 158 felt symptoms after attempting to quit smoking before banning.

**85 out of 100 felt symptoms after quitting smoking during banning.

†One smoker may have more than one feeling at the same time. 
The main reasons for smoking cessation for those who successfully quit smoking during banning were the expensive price $(36 \%)$, fear of punishment, and financial fines $(33 \%)$, in addition to other reasons mentioned in Table 3. Table 4 shows no significant association between the rate of quitting smoking and the other basic characteristics of the studied sample, even with those who had chronic diseases.

Table 3: Reasons for quitting smoking during banning.

\begin{tabular}{lcc}
\hline Reasons for quitting smoking & No. & (\%) \\
\hline High price & 36 & $(36.0)$ \\
Fear of punishment and financial fines & 33 & $(33.0)$ \\
Health problems & 15 & $(15.0)$ \\
Unavailability of the cigarettes & 11 & $(11.0)$ \\
Family pressure and other reasons & 5 & $(5.0)$ \\
Total & $\mathbf{1 0 0}$ & $\mathbf{( 1 0 0 . 0 )}$ \\
\hline
\end{tabular}

Table 4: The relation between smoking status during banning with basic characteristics of the studied sample.

\begin{tabular}{|c|c|c|c|c|c|c|c|c|}
\hline \multirow[t]{2}{*}{ Basic characteristics } & \multicolumn{2}{|c|}{$\begin{array}{c}\text { Quitters } \\
\mathrm{N}=100\end{array}$} & \multicolumn{2}{|c|}{$\begin{array}{l}\text { Continue with } \\
\text { less number } \\
\mathrm{N}=287\end{array}$} & \multicolumn{2}{|c|}{$\begin{array}{l}\text { Continue with same } \\
\text { or more number } \\
\qquad=133\end{array}$} & \multirow[t]{2}{*}{ Total } & \multirow[t]{2}{*}{$P$ value } \\
\hline & No. & (\%) & No. & (\%) & No. & (\%) & & \\
\hline \multicolumn{9}{|l|}{ Place of birth } \\
\hline Urban & 94 & (19.9) & 272 & (57.5) & 107 & (22.6) & 473 & 0.956 \\
\hline Rural & 6 & $(22.2)$ & 15 & $(55.6)$ & 6 & (22.2) & 27 & \\
\hline \multicolumn{9}{|l|}{ SES } \\
\hline Low & 27 & (16.3) & 99 & $(59.6)$ & 40 & (24.1) & 166 & 0.472 \\
\hline Medium & 51 & (20.5) & 144 & $(57.8)$ & 54 & (21.7) & 249 & \\
\hline High & 22 & (25.9) & 44 & $(51.8)$ & 19 & (22.4) & 85 & \\
\hline \multicolumn{9}{|l|}{ BMI } \\
\hline Normal and underweight & 33 & (17.5) & 110 & $(58.2)$ & 46 & (24.3) & 189 & 0.624 \\
\hline Overweight & 44 & (22.1) & 116 & $(58.3)$ & 39 & (19.6) & 199 & \\
\hline Obese & 23 & (20.5) & 61 & $(54.5)$ & 28 & (25.0) & 112 & \\
\hline \multicolumn{9}{|l|}{ Marital status } \\
\hline Single & $22.2 \%$ & $(27.1)$ & 53 & (49.5) & 25 & (23.4) & 107 & $0.113^{*}$ \\
\hline Married & $22.2 \%$ & $(18.6)$ & 226 & $(59.9)$ & 81 & (21.5) & 377 & \\
\hline Widowed & 1 & (11.1) & 4 & (44.4) & 4 & (44.4) & 9 & \\
\hline Divorced & 0 & $(0.0)$ & 4 & $(57.1)$ & 3 & $(42.9)$ & 7 & \\
\hline \multicolumn{9}{|l|}{ Physical activity } \\
\hline None & 43 & $(17.0)$ & 146 & (57.7) & 64 & (25.3) & 253 & 0.365 \\
\hline On occasion & 27 & $(23.1)$ & 69 & $(59.0)$ & 21 & (17.9) & 117 & \\
\hline Once/week & 15 & $(27.3)$ & 31 & $(56.4)$ & 9 & $(16.4)$ & 55 & \\
\hline 2-3times/week & 10 & $(27.0)$ & 18 & $(48.6)$ & 9 & $(24.3)$ & 37 & \\
\hline Daily & 5 & $(13.2)$ & 23 & $(60.5)$ & 10 & (26.3) & 38 & \\
\hline \multicolumn{9}{|l|}{ Chronic diseases } \\
\hline No & 73 & (19.3) & 221 & (58.5) & 84 & (22.2) & 378 & 0.680 \\
\hline Yes & 27 & (22.1) & 66 & (54.1) & 29 & $(23.8)$ & 122 & \\
\hline
\end{tabular}

-Pearson Chi Square test was used to calculate the $P$ value in this table except for $P$ labeled by * where Fisher's Exact test was used. 
Table 5 shows that the rate of quitting smoking was significantly higher among participants with the shorter duration of smoking before the banning period $(<9$ years $), \quad(P=0.006)$, those who had a history of quitting smoking before banning $(P=0.001)$, and significantly associated with the light intensity of smoking $(P=0.003)$. Also, the rate of quitting smoking was significantly higher among participants who have smoking relatives other than first degree with $(P=0.025)$. No significant association was detected between the rate of quitting smoking and other characters.

Table 5: The relation between smoking status during banning with some smoking characteristics.

\begin{tabular}{|c|c|c|c|c|c|c|c|c|}
\hline \multirow[t]{2}{*}{$\begin{array}{l}\text { Smoking } \\
\text { characteristic }\end{array}$} & \multicolumn{2}{|c|}{ Quitters } & \multicolumn{2}{|c|}{$\begin{array}{l}\text { Continue with } \\
\text { less number }\end{array}$} & \multicolumn{2}{|c|}{$\begin{array}{l}\text { Continue with same } \\
\text { or more number }\end{array}$} & \multirow[t]{2}{*}{ Total } & \multirow[t]{2}{*}{$P$ value } \\
\hline & No. & $\%$ & No. & $\%$ & No. & $\%$ & & \\
\hline \multicolumn{9}{|l|}{ Duration } \\
\hline$<5$ & 26 & $(28.3)$ & 50 & $(54.3)$ & 16 & $(17.4)$ & 92 & 0.006 \\
\hline $5-9$ & 27 & $(28.4)$ & 56 & $(58.9)$ & 12 & $(12.6)$ & 95 & \\
\hline $10-14$ & 16 & $(20.3)$ & 43 & $(54.4)$ & 20 & $(25.3)$ & 79 & \\
\hline $15-19$ & 7 & $(11.5)$ & 39 & $(63.9)$ & 15 & $(24.6)$ & 61 & \\
\hline$\geq 20$ & 24 & $(13.9)$ & 99 & $(57.2)$ & 50 & $(28.9)$ & 173 & \\
\hline \multicolumn{9}{|l|}{ Family smoking } \\
\hline No & 28 & $(24.1)$ & 64 & $(55.2)$ & 24 & $(20.7)$ & 116 & 0.434 \\
\hline Yes & 72 & $(18.8)$ & 223 & $(58.1)$ & 89 & $(23.2)$ & 384 & \\
\hline \multicolumn{9}{|c|}{ Degree of family relation } \\
\hline First degree relative & 32 & $(19.0)$ & 109.0 & $(64.9)$ & 27 & $(16.1)$ & 168 & 0.025 \\
\hline $\begin{array}{l}\text { Relatives other than } \\
\text { first degree }\end{array}$ & 14 & $(25.0)$ & 26.0 & $(46.4)$ & 16 & $(28.6)$ & 56 & \\
\hline Both & 26 & $(16.3)$ & 88.0 & $(55.0)$ & 46 & $(28.8)$ & 160 & \\
\hline \multicolumn{9}{|l|}{ Smoking friends } \\
\hline No & 4 & $(30.8)$ & 7 & $(53.8)$ & 2 & $(15.4)$ & 13 & $0.592^{*}$ \\
\hline Yes & 96 & $(19.7)$ & 280 & $(57.5)$ & 111 & $(22.8)$ & 487 & \\
\hline \multicolumn{9}{|l|}{ Type of smoking } \\
\hline Cigarettes & 77 & (19.9) & 222 & $(57.4)$ & 88 & $(22.7)$ & 387 & $0.069^{*}$ \\
\hline Cigarettes and Nargile & 14 & $(16.3)$ & 56 & $(65.1)$ & 16 & $(18.6)$ & 86 & \\
\hline Nargile & 7 & $(29.2)$ & 8 & (33.3) & 9 & $(37.5)$ & 24 & \\
\hline $\begin{array}{l}\text { Electronic cigarette \& } \\
\text { others. }\end{array}$ & 2 & $(66.7)$ & 1 & $(33.3)$ & 0 & $(0.0)$ & 3 & \\
\hline \multicolumn{9}{|c|}{ History of quitting smoking before banning it } \\
\hline No & 47 & $(13.7)$ & 208 & $(60.8)$ & 87 & $(25.4)$ & 342 & $<0.001$ \\
\hline Yes & 53 & $(33.5)$ & 79 & $(50.0)$ & 26 & $(16.5)$ & 158 & \\
\hline \multicolumn{9}{|l|}{ Smoking intensity } \\
\hline Light smoker & 17 & 17 & $39.5 \%$ & $34.9 \%$ & 11 & $25.6 \%$ & 43 & 0.003 \\
\hline Medium smoker & 19 & 19 & $24.7 \%$ & $54.5 \%$ & 16 & $20.8 \%$ & 77 & \\
\hline Heavy smoker & 64 & 64 & $16.8 \%$ & $60.5 \%$ & 86 & $22.6 \%$ & 380 & \\
\hline Total & 100 & 100 & $(20.0)$ & (57.4) & 113 & (22.6) & 500 & \\
\hline
\end{tabular}

-Person Chi Square test was used to calculate $P$ value in this table except for $p$ labeled by * where Fisher's Exact test was used. 


\section{Discussion}

Smoking cessation is a controversial topic, as many factors play a role in the process in addition to the interaction between physical and psychological dependence. This study was done in an attempt to answer some of the queries about the behavior of smokers after the obligatory banning of cigarettes in Mosul city. There are still few research experiences investigating the impact of the smoking banning policies worldwide. A recent study carried out in the USA did not find evidence that smoking bans have a real effect on smoking behavior. ${ }^{8}$ An Italian study found that, immediately after the introduction of such a law, Italian smokers changed their habits (reduced smoking prevalence by $1.3 \%$, and daily cigarettes consumption by $8 \%) .{ }^{9}$ Studies suggest that smoke-free legislation in the UK was associated with a greater number of quit attempts in England, ${ }^{10}$ and increased sales of nicotine replacement therapy (NRT) and contacts with smoking cessation services in the months prior to implementation in Scotland. ${ }^{11}$ However, little is known about how many people were actually successful in quitting smoking and the long-term effects of smoking bans on cessation and relapse of the general population if a universal ban was applied..$^{11}$ In this study, there was no significant association between age and smoking cessation rate, while a study done in Italy showed that the quit ratio increased significantly for those aged $>23$ years. ${ }^{12}$ The absence of a significant association between the place of birth and quitting tobacco in this study highlights the importance of the spread of the epidemic of tobacco use. Regarding the smoking's harmful effects on the economic development of society, the smokers in Iraq would have to spend $3.34 \%$ of their average income to purchase cigarettes. ${ }^{13}$ One of the important findings of this study is the crucial role of social norms and economic state in governing people's behavior. Initially, the peers and social pressures made the participants start smoking, while during banning, the main reason for quitting was the high price. The quitting rate was significantly higher among participants who have smoking relatives other than first degree. The results of this study coincide with others who suggest that having more smokers in social networks may serve as a barrier to smoking cessation. ${ }^{14}$ There was no significant association between the rate of quitting smoking and all the studied socioeconomic indicators. No significant association was detected between quitting smoking and BMI, physical activity, nor with those who had chronic diseases. Physical activity decreases the desire to smoke, reduces cravings and withdrawal symptoms. ${ }^{15}$ In our study, $>34 \%$ of the participants experienced increasing appetite after quitting smoking. Some smokers also attempt to cope with nicotine withdrawal by substituting eating for the [hand to mouth] behavior of smoking which can lead to an increase in caloric intake. ${ }^{16}$ Results showed that there was a significant association between the amount of smoking before the banning period and the rate of quitting. We relied on dividing the amount of smoking into three categories according to the number of cigarettes per day rather than the amount of smoke inhaled per puff. This was done because of the study design on the one hand and shortage of resources on the other hand. ${ }^{17}$ The study showed a strong association between the duration of smoking before the banning period ( $<9$ years) and the rate of quitting. This coincides with a study done in Italy which showed that smokers who started smoking before the age of 15 were less likely to quit, and they smoke more cigarettes. ${ }^{12}$ About one third of the studied sample had tried to quit smoking at least once in their life. The mean number of times of trying to quit was 2.37 times, ranging from 1-13 times throughout the period before banning. The minimum period between quitting and return to smoking was several days, and the maximum was 16.67 years. 
The information about the quitting attempts can be used as messages to encourage the smokers to stay engaged in the process of quitting. Alternatively, knowing the average number of quit attempts may be a deterrent to continue trying. For instance, the American Cancer Society suggests that it takes $8-10$ quit attempts. ${ }^{18}$ The study showed that $20 \%$ of the smokers had stopped smoking during the period of banning, $55.4 \%$ of the participants continued smoking, but with fewer cigarettes. The rest continued smoking but with the same or higher number of cigarettes. Comparing these results with findings of combined surveys done in Italy in terms of observance of the legislation and change of habits, $75 \%$ of the Italian population reported that the smoking ban was respected in workplaces. After the implementation of the tobacco regulation, approximately $10 \%$ of Italians mentioned that they went to bars/cafes and restaurants more frequently than before the legislation, and approximately $7 \%$ less frequently. ${ }^{19}$ The participants in our study had experienced different feelings after quitting smoking, like headache, nervousness, and other symptoms. Findings from the "international tobacco control four country survey' supported the hypothesis that most smokers can quit without experiencing depressive symptoms, and if present, it varies by age and prior symptoms of the smokers. ${ }^{20}$ The current study included men aged 18 years or more only, so its results can neither be generalized to those aged less than 18 years nor to women. The sample size was not measured because there was no previous study of the same manner. Accordingly, the rate of cessation cannot be estimated. It is worth mentioning that even if we consider the rate as $50 \%$ (which gives us the largest sample size), the estimated sample would be 384 persons (considering the precision as 5\% and the power as $80 \%$ ) according to Epi info computer program. Inability to take a random sample owing to the safety issues in the city. To overcome this, the researchers collected their sample from different places in Mosul and different classes without prior knowledge about the smoking history of the interviewee. Hence, the sample is, more or less, considered to be relatively random. The strength of this manuscript is that no similar study had been done before worldwide.

\section{Conclusion}

Only one fifth of the smokers stopped smoking during banning, and the majority of them returned to smoking after the liberation of Mosul. The majority of smokers stopped smoking suddenly. Smoking cessation is still a challenge to public health practitioners, as it is multi-factorial. Health education and anti-smoking legislation are highly recommended.

\section{Competing interests}

The authors declare no competing interests.

\section{References}

1. WHO. WHO report on the global tobacco epidemic, 2011: warning about the dangers of tobacco. Geneva: World Health Organization; 2011.

2. WHO. Tobacco: Leading cause of death, illness and impoverishment, USA. Geneva: WHO; 2019. (Accessed March 9, 2018, at https://www.who.int/news-room/fact-sheets/ detail/tobacco).

3. What you need to know when quitting smoking. 2013. (Accessed June 11, 2021, at https://www.swedish.org/ /media/images/ swedish/pdf/sci_smokingcessationpatients $\%$ 20pdf.pdf).

4. Piper ME, Smith SS, Schlam TR, Fleming MF, Bittrich AA, Brown JL, et al. Psychiatric disorders in smokers seeking treatment for tobacco dependence: Relations with tobacco dependence and cessation. J Consult Clin Psychol 2010; 78(1):13.

5. Behrakis $P$, Vardavas $C$, Papadakis $S$, editors. TOB-G: Tobacco cessation guidelines for high risk populations. Athens, Greece: Hellenic Center for Disease Control and Prevention (KEELPNO); 2017. P. 9.

6. Wilkins R, Black D, Buddelmeyer $H$. The effects of smoking ban regulations on individual smoking rates. Melbourne Institute of Applied Economic and Social Research, The University of 
Melbourne; 2005.

7. Omer W, Al-Hadithi TS. Developing a socioeconomic index for health research in Iraq. East Mediterr Health J 2017; 23(10):670-6.

8. Adda J, Cornaglia F. The effect of bans and taxes on passive smoking. American Economic Journal: Applied Economics 2010; 2(1):1-32.

9. Buonanno P, Ranzani M. Thank you for not smoking: evidence fromthe Italian smoking ban. Health Policy 2013; 109(2):192-9.

10. Hackshaw L, McEwen A, West R, Bauld L. Quit attempts in response to smoke-free legislation in England. Tobacco control 2010; 19(2):160-4.

11. Lewis SA, Haw SJ, McNeill A. The impact of the 2006 Scottish smoke-free legislation on sales of nicotine replacement therapy. Nicotine Tob Res 2008; 10:1789-92.

12. Pieroni L, Muzi G, Quercia A, Lanari D, Rundo C, Minelli $L$, et al. Estimating the smoking ban effects on smoking prevalence, quitting and cigarette consumption in a population study of apprentices in Italy. Int $\mathrm{J}$ Environ Res Public Health 2015; 12(8):9523-35.

13. Iraq Tobacco atlas. (Accessed March 9, 2018, at: https://tobaccoatlas.org/country/iraq).

14. Hiscock R, Dobbie F, Bauld L. Smoking cessation and socioeconomic status: an update of existing evidence from a national evaluation of English stop smoking services. Biomed Research International 2015; 2015:274056.

15. Kujala UM, Kaprio J, Rose RJ. Physical activity in adolescence and smoking in young adulthood: a prospective twin cohort study. Addiction 2007; 102(7):1151-7.

16. Bush T, Lovejoy JC, Deprey M, Carpenter KM. The effect of tobacco cessation on weight gain, obesity, and diabetes risk. Obesity 2016; 24(9):1834-41.

17. Kouvonen A, Kivimäki $M$, Virtanen $M$, Pentti J, Vahtera J. Work stress, smoking status, and smoking intensity: an observational study of 46 190 employees. J Epidemiol Community Health 2005; 59(1):63-9.

18. Chaiton M, Diemert L, Cohen JE, Bondy SJ, Selby $P$, Philipneri $A$, et al. Estimating the number of quit attempts it takes to quit smoking successfully in a longitudinal cohort of smokers, BMJ 2016; 01:10-45.

19. Tramacere I, Gallus S, Fernandez E, Zuccaro P, Colombo P, La Vecchia C. Medium-term effects of Italian smoke-free legislation: findings from four annual population-based surveys. J Epidemiol Community Health 2009; 63(7):559_ 62.

20. Cooper J, Borland $\mathrm{R}$, Yong $\mathrm{HH}$, Fotuhi $\mathrm{O}$. The impact of quitting smoking on depressive symptoms: findings from the International Tobacco Control Four-Country Survey. Addiction 2016; 111(8):1448-56. 